\title{
Morphogenetic aspects of the septomarginal trabecula in the human heart
}

Adam Kosiński ${ }^{1}$, Dariusz Kozłowski², Janusz Nowiński', Ewa Lewicka², Alicja Dąbrowska-Kugacka², Grzegorz Raczak², Marek Grzybiak ${ }^{1}$

1Department of Clinical Anatomy, Medical University of Gdansk, Poland
2Department of Cardiology and Electrotherapy, Medical University of Gdansk, Poland

Submitted: 11 July 2010

Accepted: 27 August 2010

Arch Med Sci 2010; 6, 5: 733-743

DOI: $10.5114 /$ aoms.2010.17089

Copyright ( 2010 Termedia \& Banach

\author{
Corresponding author: \\ Dariusz Kozłowski MD, PhD \\ Department of Cardiology \\ and Electrotherapy \\ Medical University of Gdansk \\ ul. Dębinki 7 \\ 80-211 Gdansk, Poland \\ Phone: +48 583493910 \\ E-mail: dkozl@gumed.edu.pl
}

\begin{abstract}
Introduction: The septomarginal trabecula is a constant element of the anatomy of the human heart, which connects the interventricular septum and the anterior wall of the right ventricle. Considering the diversity of opinions about the structure and numerous studies suggesting its important role in haemodynamics and conduction of electrical impulses in the heart, we decided to study this element in detail.

Material and methods: The research was conducted on 220 human hearts. Attention was mainly paid to the structure and topography of the trabecula. Its relation to the anterior papillary muscle was also a part of the study.

Results: The presence of this morphologically diverse element was confirmed in each of the studied hearts. In most cases the trabecula originated from the upper part of the interventricular septum, separating at an angle increasing proportionally to the number of branches of the crista supraventricularis as well as the number of secondary trabeculae. The criteria established for the study, which included the course of the trabecula in the lumen of the right ventricle and its relation to the anterior papillary muscle, let us distinguish 4 types of septomarginal trabecula (I, II, III, IV). The most common was type III, the undivided trabecula, tightly connecting with the anterior papillary muscle.

Conclusions: Based on the results of the following study we propose a hypothesis on the genesis of respective parts of the septomarginal trabecula and a plausible sequence of changes they undergo during human ontogenesis and phylogenesis of the primates.
\end{abstract}

Key words: septomarginal trabecula, crista supraventricularis, morphology, human heart.

\section{Introduction}

The trabeculae carneae constitute numerous muscle bundles running longitudinally or obliquely, located on the inner surface of the ventricles. The trabeculae carneae begin to form at a rather early stage of prenatal development - their delicate structure can be observed at the $4^{\text {th }}-5^{\text {th }}$ week of fetal age [1]. Firstly, two layers start to develop within the primary myocardium: a compact one (the peripheral layer) and a spongy one (the medial layer). The intense division of the cardiomyocytes of the spongy layer leads to the formation of the typical trabeculae. The local, radial concentration of these elements forms papillary muscles, which further, within the area of the atrioventricular outlets, transform into bundles 
known as chordae tendineae [2]. At the $9^{\text {th }}$ week of fetal age one can already distinguish the septomarginal trabecula and the anterior papillary muscle of the right ventricle [3].

The septomarginal trabecula found in all human hearts as well as other primates and mammals educes from the muscle band of the interventricular septum, begins below the septal end of the crista supraventricularis and runs towards the anterolateral wall of the ventricle.

In spite of numerous studies devoted to the septomarginal trabecula, the opinion of researchers is not uniform. The controversies focus mostly on its structure, phylogenesis, and function. Only a few papers precisely describe its morphology, but the still incoherent nomenclature imposes some significant limitations. In 1837 King named it the "moderator band" since, according to his concept, the trabecula limited the excessive expansion during diastole of the right ventricle [4]. The term "septomarginal trabecula" was first used by Tandler [5] based on its attachments: proximal (the septum), and distal (the wall). Nowadays, both terms are used interchangeably $[4,6]$.

The analyses of the functional characteristics and probable clinical implications of the pathology of the moderator band seem to be very interesting. It is believed that along with the crista supraventricularis it separates the blood's inflow and outflow, playing a significant role in emptying the right ventricle of blood during systole. Consequently, the hypertrophy of those structures which often accompanies congenital defects can cause some haemodynamic disorders in the right ventricle of the heart $[7,8]$. Moreover, there are numerous studies confirming the presence of bifurcations of the right branch of His' bundle, as a constant element of the septomarginal trabecula. Bargmann [9] precisely describes the course of the conduction system fibres in the

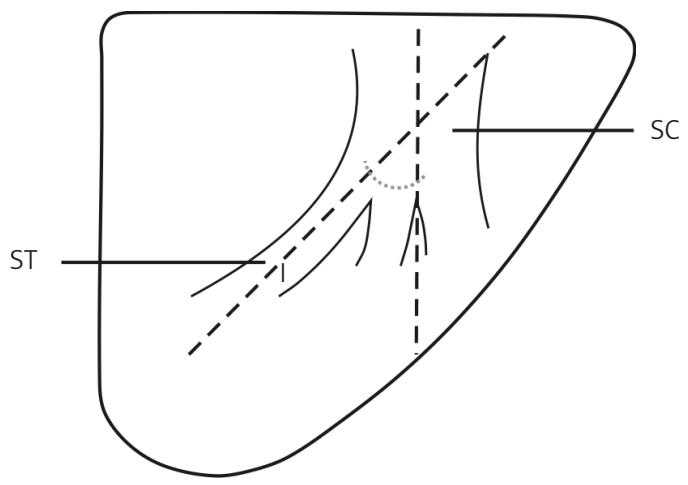

Figure 1. The angle of the septomarginal trabecula branching from the interventricular septum, between the long axis of the trabecula and the long axis of the crista supraventricularis

SC - lower part of the crista supraventricularis, ST (I) septomarginal trabecula right ventricle, with a detailed division of the right bundle branch into the specific bunches. Thus, some probable pathologies occurring within the band, most often of ischaemic aetiology, can constitute an important aetiology of conduction disturbances of the heart [10].

The study presented below is a continuation of our previous research focused on the problem of the crista supraventricularis and the septomarginal trabecula [11]. However, since our last paper considered the topographical interrelation between both structures, the present study is devoted to the morphological aspects of the trabecula. The three objectives of the work are as follows: 1) morphological analysis of the trabecula in the hearts of fetuses, children and adults; 2) distinguishing particular types using topographic criteria and its relation to the anterior papillary muscle, and finally 3) description of its differentiation during human ontogenesis.

\section{Material and methods}

The study was carried out on the material of ethanol-formalin fixed human hearts, both sexes: 60 fetal hearts aged from the $12^{\text {th }}$ to the $32^{\text {nd }}$ week of prenatal life, 60 hearts of children aged from 1 day to 14 years, and 100 hearts of adults aged from 19 to 79 years.

The menstrual age of fetuses was estimated on the basis of the V-tub length, according to the data proposed by Scammon \& Calkins [12]. The hearts were obtained from forensic or anatomopathological dissections. Only organs with no gross anatomical or congenital defects were examined.

The incision ran from the apex of the right ventricle, along its lateral margin, and through the posterior leaflet of the tricuspid valve. Then, the right atrium was opened along the lower margin of the auricle. After opening the ventricle, its interior was carefully inspected. A binocular magnifying glass was used to study the hearts obtained from fetuses and small children. Special attention was paid to the shape of the septomarginal trabecula. The subject of analysis included the angle between the moderator band and interventricular septum (located between the longitudinal axis of the trabecula and the longitudinal axis of the crista supraventricularis - Figure 1). The hearts were divided into three groups depending on the value of the angle. In the first group (A) the angle ranged from 0 to 30 degrees, in the second (B) from 31 to 60 degrees, and in the third (C) from 61 to 90 degrees (Figure 2A).

Another task was to examine the level of septomarginal trabecula branching, defined as the ratio of the height of the proximal attachment of the trabecula (a) to the height of the right ventricle (b) (Figure 3). The measurements were taken at the 
A
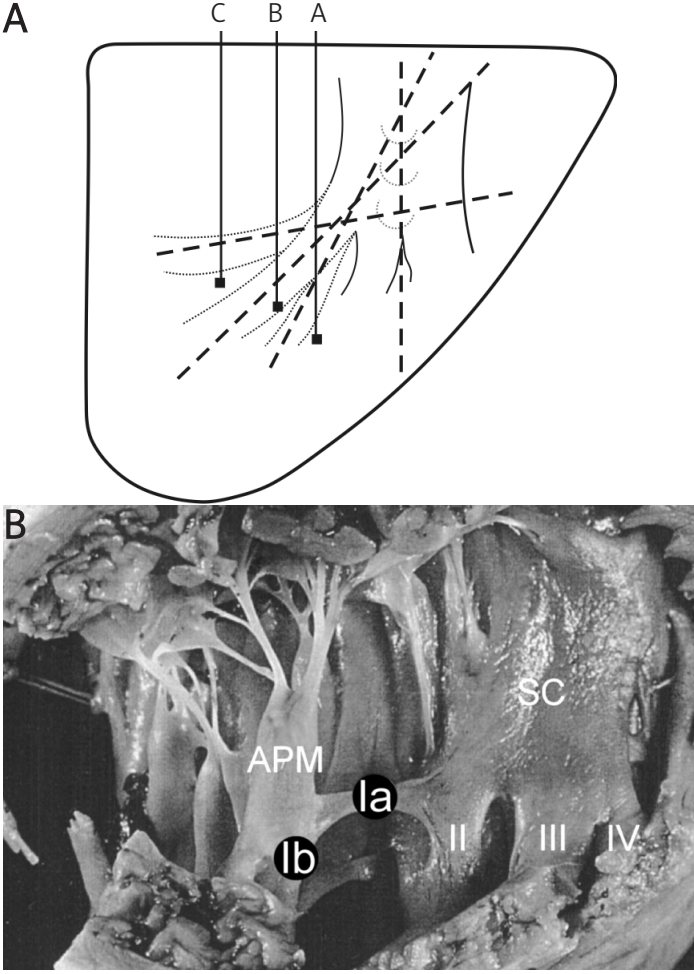

Figure 2. A - The angles of branching of the septomarginal trabecula from the interventricular septum. Group A from 0 to 30 degrees, group B from 31 to 60 degrees, group $C$ from 61 to 90 degrees. $\mathrm{B}$ - Interior of the right ventricle, division of the crista supraventricularis into four branches; sub-type IVb of the septomarginal trabecula ( $\hat{0}, 38 \mathrm{yrs})$

APM - anterior papillary muscle, SC - lower part of the crista supraventricularis, la in black circle - septo-papillary segment of the septomarginal trabecula, Ib in black circle - papillomarginal segment of the septomarginal trabecula, II - second branch of the SC, III - third branch of the SC, IV - fourth branch of the SC

base of the right ventricle and at the attachment of the tricuspid valve leaflets, towards the apex of the ventricle. The size and the course of the septomarginal trabecula inside the lumen of the ventricle were also a subject of analysis. Also, in 100 hearts of adults the thickness of the structure was evaluated at the region of its branching from the crista supraventricularis. Due to the small dimensions of the hearts, the respective measurements were not taken for fetuses and children. The evaluation of the location of the trabecula with respect to the anterior papillary muscle was essential for proper classification.

Simultaneously, schematic diagrams, figures and photographs were documented. Most of the observations were statistically analysed with the chi-square test.

\section{Results}

The septomarginal trabecula emerging due to differentiation of the lower pole of the crista

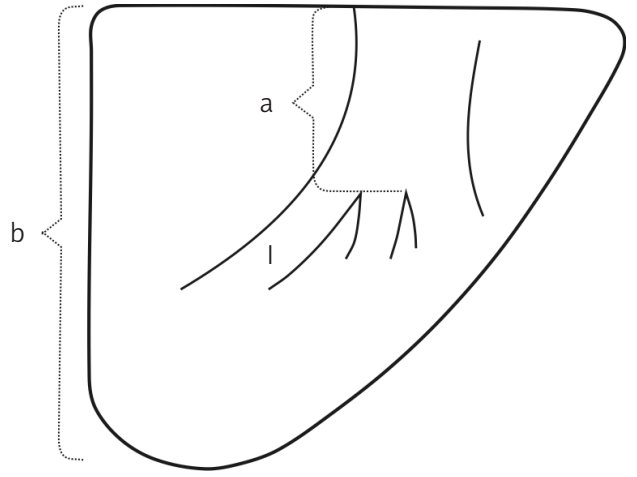

Figure 3. The level of septomarginal trabecula branching from the interventricular septum, described as the ratio of the height of the location of the proximal attachment of the trabecula (a) to the height of the right ventricle (b) $-a / b$ I-septomarginal trabecula

supraventricularis is the first trabecula carnea forming at the side of the atrioventricular outlet (Figure 4). Its occurrence was confirmed in all studied hearts, and its size and course were highly heterogeneous. The thickness of the trabecula also varied between the studied groups. The obtained observations allowed some particular relations to be established. In fetal hearts of small volume the septomarginal trabecula was relatively large, occupied a significant portion of the right ventricular lumen, and was easily distinguishable from other anatomical elements of its interior. In contrast, in the large ventricles of adult hearts, often but not always it was a small, less developed structure, occupying a smaller volume of the lumen when compared to the hearts of fetuses or children. The presented observations do not establish absolute values of measurements. They show a tentative proportion - a ratio of the size (volume) of the septomarginal trabecula to the size (volume) of the lumen of the right ventricle. Significant differences in the thickness of this structure, ranging from 2 to 10 millimetres, were observed between individuals. Table I presents the numerical distribution of the frequency of occurrence of different thicknesses (in $\mathrm{mm}$ ) in the group of 100 adults. In many cases, along its course from the interventricular septum to the interior surface of the anterior wall of the right ventricle, the septomarginal trabecula became thinner. This was typical mainly in cases where the septomarginal trabecula, due to its division, gave rise to some secondary branches running towards the anterior wall (Figure 5). However, in many cases its crosssectional size, along the whole course of the trabecula in the right ventricle, remained almost unchanged. It must be clearly stated that in all cases the moderator band was a fully developed and solid muscle structure. 

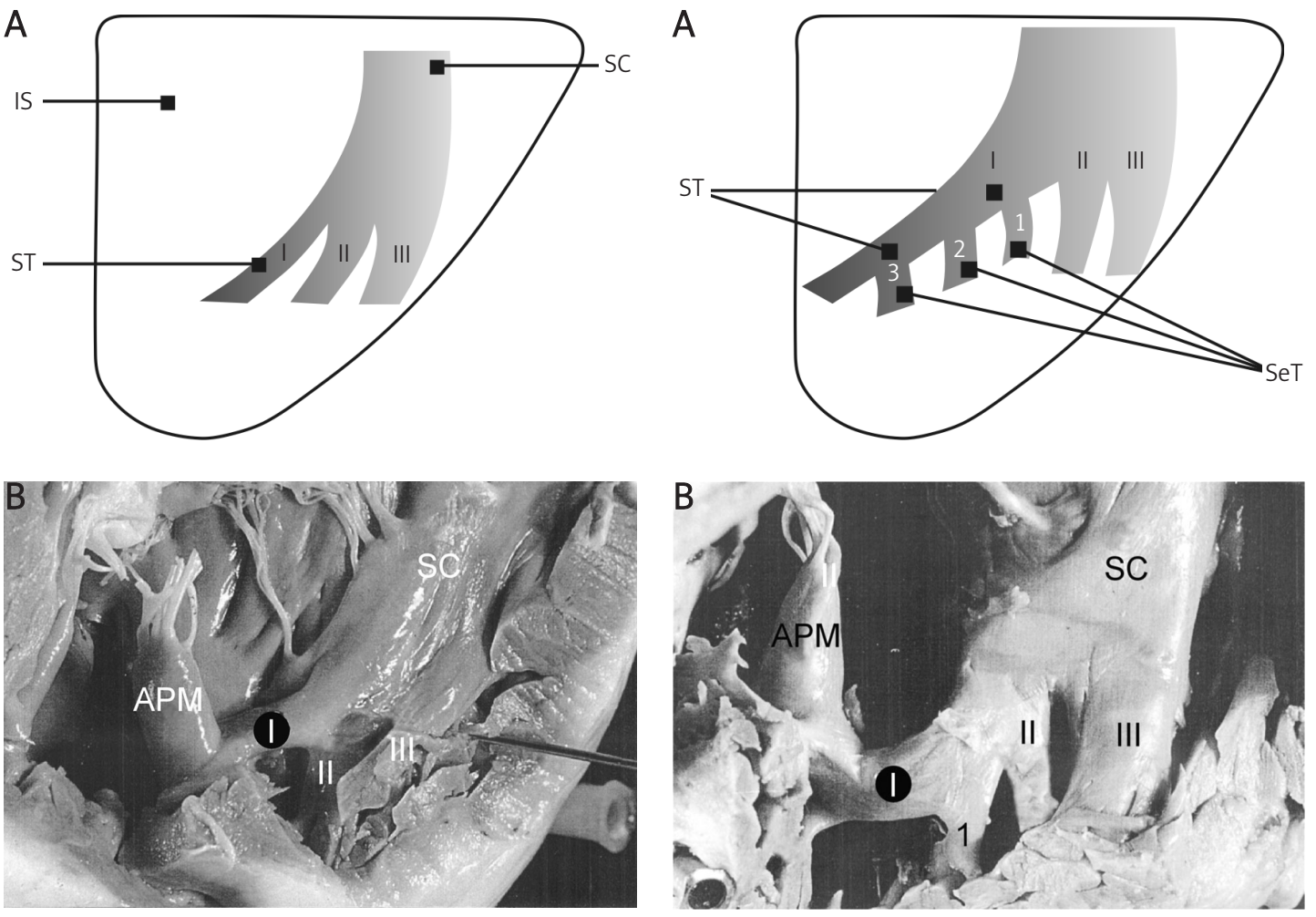

Figure 4. A - Schematic diagram of right ventricle interior, division of the crista supraventricularis into three branches (I, II, III). B - Interior of the right ventricle, division of the crista supraventricularis into three branches; sub-type IIb of the septomarginal trabecula ( $\hat{0}, 51 \mathrm{yrs})$

IS - interventricular septum, SC - lower part of the crista supraventricularis, ST (I) - septomarginal trabecula. APM anterior papillary muscle, SC - lower part of the crista supraventricularis, I in black circle - septomarginal trabecula, II - second branch of the SC, III - third branch of the SC

Table I. Thickness of the septomarginal trabecula in the group of adults

\begin{tabular}{|cc|}
\hline Thickness $[\mathrm{mm}]$ & Number of hearts \\
\hline 2 & 7 \\
\hline 3 & 19 \\
\hline 4 & 27 \\
\hline 5 & 10 \\
\hline 6 & 11 \\
\hline 7 & 8 \\
\hline 8 & 6 \\
\hline 9 & 8 \\
\hline 10 & 4 \\
\hline & 100 \\
\hline
\end{tabular}

Another subject to assess was the height of the band's proximal attachment to the interventricular septum. In most cases, i.e. in 14 out of 60 examined fetus hearts, the septomarginal trabecula had its beginning at the upper $1 / 3$ or the middle of the
Figure 5. A - Division of the crista supraventricularis into three branches (I, II, III), with the presence of the secondary trabeculae (SeT). B - Interior of the right ventricle, division of the crista supraventricularis into three branches with the presence of the secondary trabecula; sub-type Illa of the septomarginal trabecula ( $\delta, 58 \mathrm{yrs})$

APM - anterior papillary muscle, SC-lower part of the crista supraventricularis, I in black circle - septomarginal trabecula II - second branch of the SC, III - third branch of the SC 1 - secondary trabecula

height of the right ventricle (23.3\% for each), and in another 12 cases in the upper $2 / 5$ of the height (20\%). In children's hearts, in almost half of the cases the trabecula had its beginning at the upper $2 / 5$ of the height of the right ventricle (28 out of 60 examined cases $-46.6 \%$ ), and in 18 cases in its upper $1 / 3$ (30\%). In the group of adults, predominantly it began at the $1 / 3$ (38 cases - 38\%) or $2 / 5$ ( 27 cases $-27 \%$ ) of the upper part of the interventricular septum. A detailed analysis is presented in Table II.

The next aspect to analyse was the assessment of the angle the trabecula formed with the interventricular septum. Within the fetus and children group $A$, the most common case constituted hearts in which the first branch of the crista supraventricularis remained undivided and did not create any secondary branches running towards the anterior wall (16 and 13 cases respectively). Additionally, in the group of children there were 4 cases with only one bifurcation deriving from the septomarginal trabecula. Within group $B$, among children and fetuses, the number 
of both undivided and divided trabeculae was similar (15 and 12 cases of fetuses, 13 and 11 of children respectively). Within the last group, $\mathrm{C}$, the ratio was as follows: fetuses -5 cases with no bifurcations and 10 with 1 branch dividing into secondary trabeculae; children -6 and 12 cases respectively. In the right ventricle of adult individuals, the scheme was less regular: with angle 0-30 deg. -20 cases with no bifurcations and 10 with dividing septomarginal trabecula; angle 3160 deg. -14 and 9 cases respectively; and finally angle 61-90 deg. -29 and 16 hearts. Table III presents detailed data regarding the frequency of the respective angles formed between septomarginal trabecula branching and the interventricular septum, taking into account the studied populations of fetuses, children and adults, as well as presence or absence of secondary trabeculae.

As mentioned before, the anterior papillary muscle, formerly known as the great one, is more or less firmly connected to the septomarginal trabecula. The trabecula deriving from the crista supraventricularis can remain in various topographical relations to that structure. Depending on the course of the septomarginal trabecula within the interior of the right ventricle and, above all, its connection and location in relation to the anterior papillary muscle, 4 morphological types were distinguished. In type I, the septomarginal trabecula of variable thickness was a solid structure, not segmented into septo-papillary and papillomarginal parts. The anterior papillary muscle was characterized by its heterogeneity and variability of its location. It was residing on a "scaffold" of vertical trabeculae deriving from either the region of the interventricular septum or the apex or the interior surface of the anterior wall of the right ventricle. A case where the anterior papillary muscle was located up the anterior wall and firmly attached to it with the septomarginal trabecula reaching the wall a bit lower was also included in that type. Thus, type I included a solid trabecula which remained undivided by the anterior papillary muscle. In the studied material such a variant was observed in
Table II. The ratio of the height of septomarginal trabecula branching from the crista supraventricularis (a) to the height of the interventricular septum (b) in the respective age groups

\begin{tabular}{|cccc|}
\hline$a / b$ & Fetuses & Children & Adults \\
\hline $1 / 6$ & 0 & 0 & 0 \\
\hline $1 / 5$ & 5 & 2 & 0 \\
\hline $1 / 4$ & 1 & 7 & 6 \\
\hline $1 / 3$ & 14 & 18 & 38 \\
\hline $2 / 5$ & 12 & 28 & 27 \\
\hline $1 / 2$ & 14 & 5 & 21 \\
\hline $3 / 5$ & 11 & 0 & 7 \\
\hline $2 / 3$ & 3 & 0 & 1 \\
\hline & 60 & 60 & 100 \\
\hline
\end{tabular}

5 fetal hearts (8.32\%), 3 children's (4.99\%), and 3 adults' (3\%). Considering the varied location of the anterior papillary muscle in the right ventricle, two sub-types were distinguished within type I. Sub-type la was a configuration where a soaring papillary muscle was located at the wall, high on the vertical trabeculae and not firmly connected with the septomarginal trabecula. Its fibres derived from the anterior wall as well as the region of the right ventricular apex (Figure 6). In sub-type Ib the anterior papillary muscle was firmly connected to the anterior wall of the right ventricle, while the septomarginal trabecula reached the muscle independently, below the attachment of the muscle. Four out of 5 type I fetal hearts were classified as sub-type la, 1 as sub-type Ib, while 2 out of 3 children's hearts were included in sub-type la and 1 in $\mathrm{lb}$. All 3 hearts of adults were classified as sub-type Ib.

Within the distinguished types II and III the septomarginal trabecula was also a solid, one-piece structure, undivided by the anterior papillary muscle. The difference between type I described above and types II and III was a tight attachment of the base of the anterior papillary muscle to the

Table III. The angle of septomarginal trabecula branching from the crista supraventricularis in the respective age groups

\begin{tabular}{|c|c|c|c|c|c|c|c|c|c|c|c|c|}
\hline \multirow{3}{*}{$\begin{array}{l}\text { Angles of } \\
\text { trabecula } \\
\text { branching }\end{array}$} & \multicolumn{4}{|c|}{ Fetuses } & \multicolumn{4}{|c|}{ Children } & \multicolumn{4}{|c|}{ Adults } \\
\hline & \multirow{2}{*}{$\begin{array}{c}\text { No } \\
\text { secondary } \\
\text { trabeculae }\end{array}$} & \multicolumn{3}{|c|}{$\begin{array}{l}\text { Secondary } \\
\text { trabeculae }\end{array}$} & \multirow{2}{*}{$\begin{array}{l}\text { No } \\
\text { secondary } \\
\text { trabeculae }\end{array}$} & \multicolumn{3}{|c|}{$\begin{array}{l}\text { Secondary } \\
\text { trabeculae }\end{array}$} & \multirow{2}{*}{$\begin{array}{c}\text { No } \\
\text { secondary } \\
\text { trabeculae }\end{array}$} & \multicolumn{3}{|c|}{$\begin{array}{l}\text { Secondary } \\
\text { trabeculae }\end{array}$} \\
\hline & & 1 & 2 & 3 & & 1 & 2 & 3 & & 1 & 2 & 3 \\
\hline $0^{\circ}-30^{\circ}$ & 18 & - & - & - & 14 & 4 & - & - & 22 & 10 & - & - \\
\hline $31^{\circ}-60^{\circ}$ & 15 & 12 & - & - & 13 & 11 & - & - & 14 & 9 & - & - \\
\hline \multirow[t]{3}{*}{$61^{\circ}-90^{\circ}$} & 5 & 7 & 3 & - & 6 & 4 & 8 & - & 29 & 1 & 12 & 3 \\
\hline & 38 & & 22 & & 33 & & 27 & & 65 & & 35 & \\
\hline & & 60 & & & & 60 & & & & 100 & & \\
\hline
\end{tabular}


A

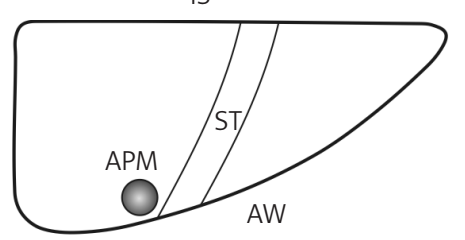

a

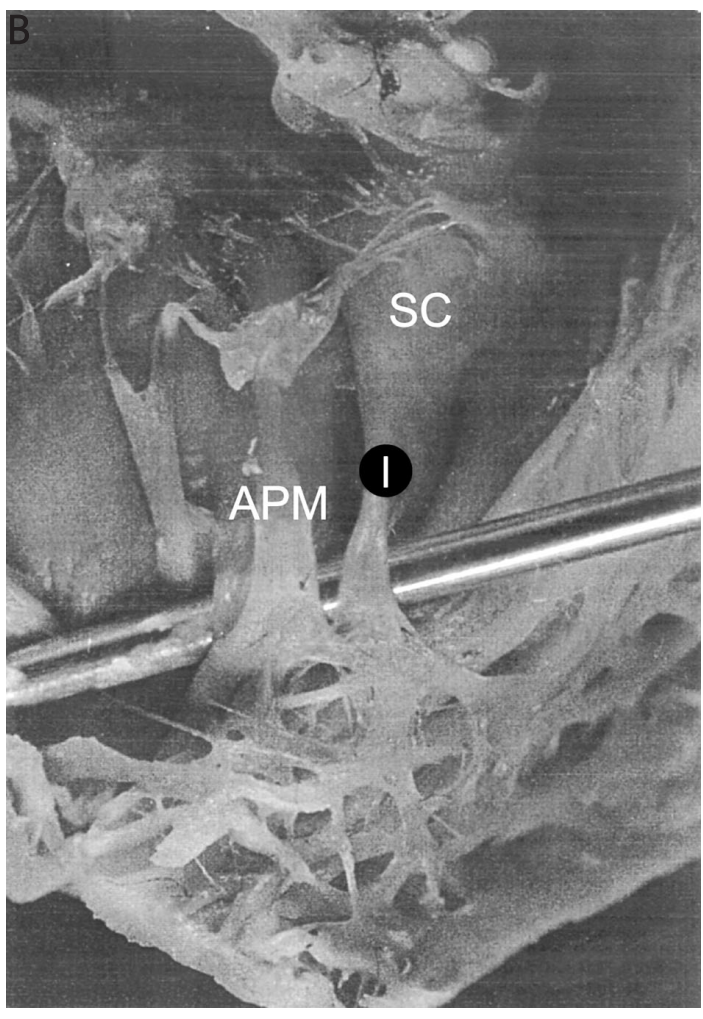

Figure 6. A - Sub-type la of the septomarginal trabecula: a) horizontal cross-section through the lumen of the right ventricle; b) sagittal cross-section through the lumen of the right ventricle. B - Interior of the right ventricle; sub-type la of the septomarginal trabecula ( $\hat{\delta}, 3 \mathrm{yrs}$ )

IS - interventricular septum, AW-anterior wall of the right ventricle, ST - septomarginal trabecula, APM - anterior papillary muscle, SC - lower part of the crista supraventricularis, I in black circle - septomarginal trabecula

anterior wall of the right ventricle present in all cases.

Type II of the trabecula was characterized by a contiguous connection of the anterior papillary muscle with the studied structure or a firm, variably advanced consolidation of both elements. Thus, the distal segment of the septomarginal trabecula partially connected with the anterior papillary muscle and partially with the anterior wall of the right ventricle. The proportions were highly variable
A

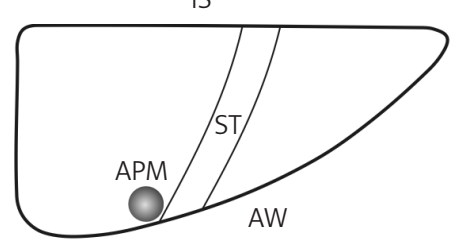

a
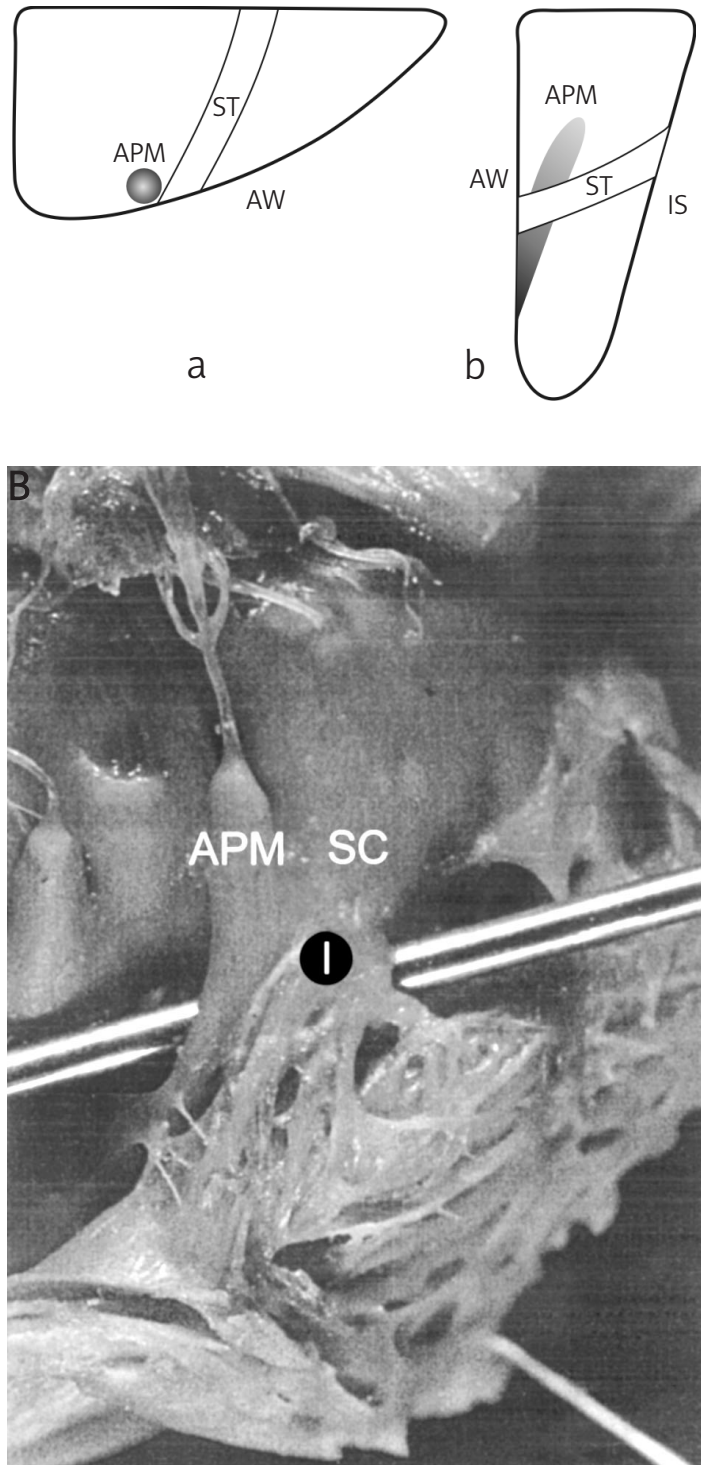

Figure 7. A - Sub-type lla of the septomarginal trabecula: a) horizontal cross-section through the lumen of the right ventricle; b) sagittal cross-section through the lumen of the right ventricle. B - Interior of the right ventricle; sub-type lla of the septomarginal trabecula ( 051 yrs)

IS - interventricular septum, AW-anterior wall of the right ventricle, ST - septomarginal trabecula, APM - anterior papillary muscle, SC - lower part of the crista supraventricularis, I in black circle - septomarginal trabecula

among individuals. Thirteen out of 60 hearts of fetuses $(21.06 \%), 9$ out of 60 hearts of children $(15 \%)$ and 8 out of 100 hearts of adults (8\%) were included in this type. Considering the degree of consolidation of those structures, two sub-types were distinguished within this group. Sub-type Ila, determined by the trabecula adjoining the muscle (Figure 7 ), was observed in 4 fetuses $(30.77 \%$ of type II group), 3 children (33.33\%) and 7 adults (87.5\%). Sub-type Ilb was characterized by a partial 
consolidation of the septomarginal trabecula and the anterior papillary muscle, while the remaining segment of the trabecula reached the anterior wall of the ventricle (Figure 4B). Such a phenomenon could be observed in 9 fetuses (69.23\%), 6 children (66.66\%) and 1 adult (12.5\%).

In type III the trunk of the muscle attached to the anterior wall was tightly connected to the distal, parietal end of the septomarginal trabecula. The frequency of occurrence of this type in the respective groups was as follows: among fetuses 40 out of 60 cases (66.65\%), among children 40 out of $60(66.6 \%)$, and 45 out of $100(45 \%)$ among adults. Considering the level of septomarginal trabecula junction with the trunk of the anterior papillary muscle, also 2 sub-types were distinguished within type III. Sub-type IIIa, where the trabecula reached almost $1 / 2$ of its height (Figure 5B), was found in 34 hearts of fetuses (85\% of all type III hearts), in 33 of children (82.5\%), and 35 of adults (77.7\%). In sub-type IIIb, both structures met together at the base of the anterior papillary muscle (Figure 8). Such a configuration was noticed in the remaining hearts: 6 out of 40 of fetuses (15\%), 7 out of 40 of children (17.5\%) and 10 out of 45 of adults that were classified as type III (22.7\%).

In the final type (IV) a septo-papillary segment connecting the interventricular septum with the anterior papillary muscle, and a papillo-marginal segment between the muscle and the anterior wall of the right ventricle, were distinguished. This type was found in 2 hearts of fetuses (3.33\%), 8 of children (13.22\%), and 44 of adults (44\%). The septopapillary part was a solid, well developed segment of the septomarginal trabecula, while the other, papillo-marginal part was characterized by high variability with regard to its development and topography. Considering the facts presented above, three sub-types were distinguished within type IV. In sub-type IVa a centrally located anterior papillary muscle divided the septomarginal trabecula into two parts. The single, solid papillo-marginal part, in terms of length and size, was similar to the septo-papillary one. In most cases it ran horizontally in the ventricle, to some extent as an elongation of the septopapillary segment (Figure 9). This configuration was not found in the hearts of fetuses, but was clearly visible in 2 cases of children and 12 of adults. In subtype IVb a well-developed and horizontally running septo-papillary segment tightly connected at its distal end with the anterior papillary muscle located parietally (Figure 2B). The papillo-marginal segment began at the base of the muscle and ran steeply towards the anterior wall and the apex of the right ventricle. Similarly to the septo-papillary one, this segment was also well developed and clearly distinguished itself from other morphological elements in gross anatomy of the right ventricle. It
A

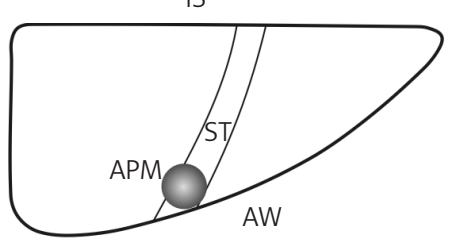

a
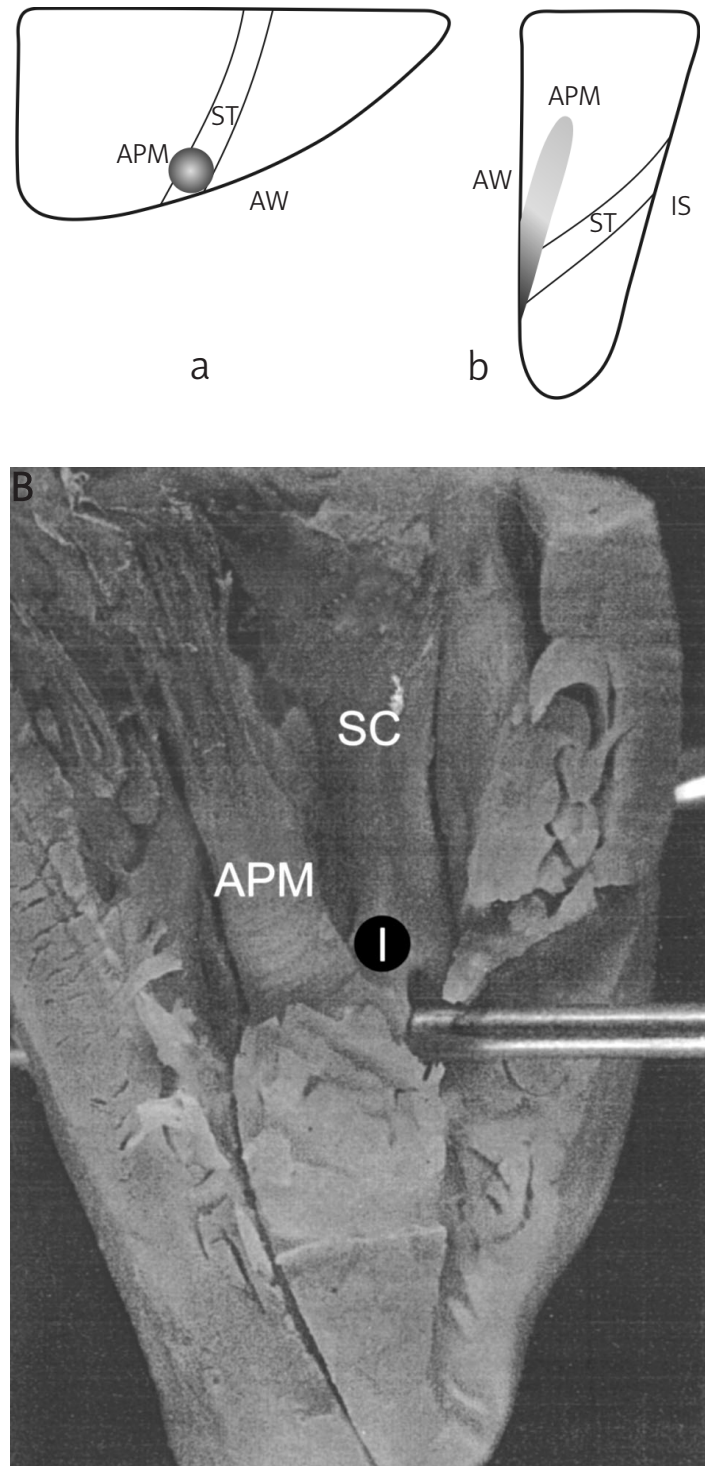

Figure 8. A - Sub-type IIIb of the septomarginal trabecula: a) horizontal cross-section through the lumen of the right ventricle; b) sagittal cross-section through the lumen of the right ventricle. B - Interior of the right ventricle; sub-type IIIb of the septomarginal trabecula $\left(\%, 19^{\text {th }}\right.$ week of fetal life) IS - interventricular septum, AW - anterior wall of the right ventricle, ST - septomarginal trabecula, APM - anterior papillary muscle, SC - lower part of the crista supraventricularis, I in black circle - septomarginal trabecula

is worth emphasizing that both segments met almost at a right angle. In the examined material, this form was found in 2 hearts of fetuses (3.33\%), 3 of children (5.0\%) and 19 of adults (19\%). The last sub-type (IVc) was characterized by the presence of a well-developed, solid septo-papillary segment running crosswise through the lumen of the ventricle. On the other hand, the papillo-marginal part created a morphologically heterogeneous structure highly variable in its size, course and - 
A

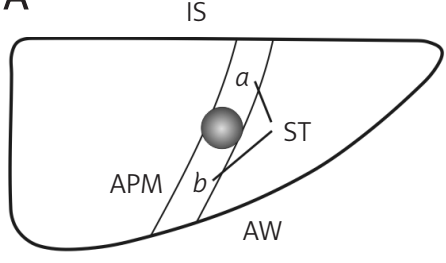

a
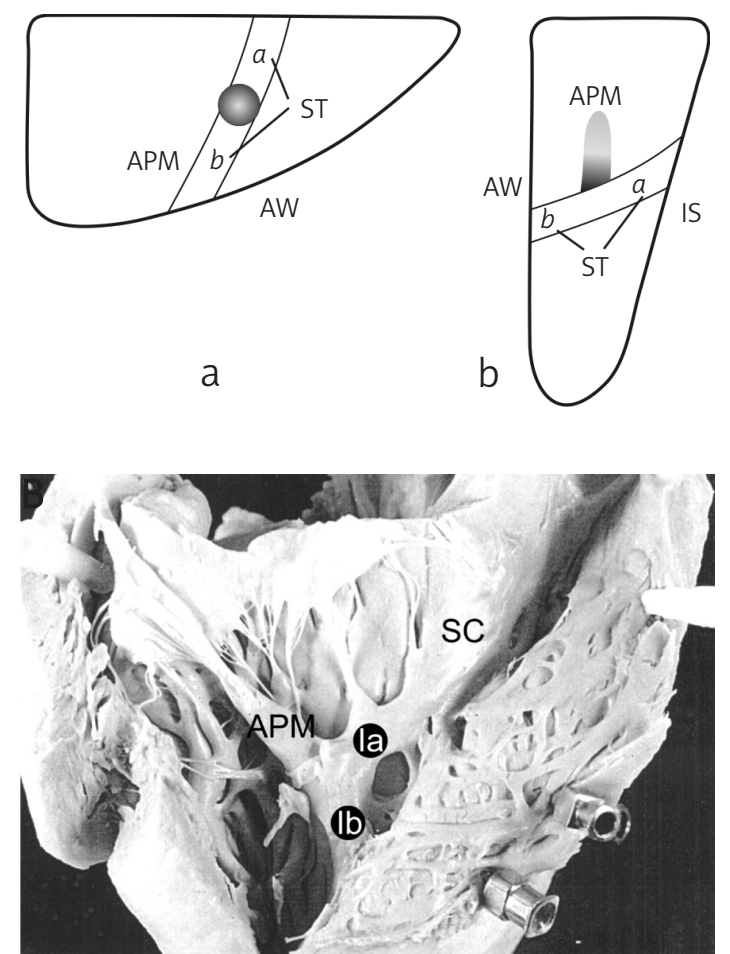

Figure 9. A - Sub-type IVa of the septomarginal trabecula: a) horizontal cross-section through the lumen of the right ventricle; b) sagittal cross-section through the lumen of the right ventricle. B - Interior of the right ventricle; sub-type IVa of the septomarginal trabecula ( $\hat{\sigma}, 40$ yrs)

IS - interventricular septum, AW-anterior wall of the right ventricle, APM - anterior papillary muscle, ST - septomarginal trabecula: $a$-septo-papillary segment, $b$-papillo-marginal segment, SC - lower part of the crista supraventricularis, la in black circle - septo-papillary segment of the septomarginal trabecula, Ib in black circle - papillo-marginal segment of the septomarginal trabecula

above all - the number of trabeculae branching from the muscle. In most cases, a few short muscle branches ran radially and by different tracks, from the area of its base towards the anterior wall. The presence of such a configuration was not confirmed in the hearts of fetuses, but it was found in 3 cases of children (5\%) and 13 hearts of adults (13\%). Table IV presents a detailed analysis.

\section{Discussion}

The trabeculae carneae, as poorly developed structures, appear for the first time in the right ventricles of birds' hearts [13]. Gradual proliferation and concentration of a net of them, creating a complex spatial arrangement, can be observed in primates. One of them, most often the largest and deriving from the crista supraventricularis as its elongation, is the septomarginal trabecula. It is a constant element of the anatomy of the human right ventricle, characterized by two features: bonding the interventricular septum with the anterior wall of the right ventricle, and its connection with the anterior papillary muscle.

Within the study group the septomarginal trabecula, though its size was variable, was always a clearly developed muscular element. Some papers suggest that in other species of primates its structure can be similar to and be mistaken for a thick false chorda tendinea [5]. Since that type of chordae, located in the left ventricle, was first studied, many synonyms have been used to name these structures: left-ventricular chordae or cords, left-ventricular chordae tendineae, muscular strings, fascicles, left-ventricular bands or moderator bands, and septomarginal trabeculae [14]. This wide range of names results in misleading nomenclature of the septomarginal trabecula. In his paper at the end of the 19th century Turner [15] described a histological structure of the "moderator band" in the left ventricle, which as the description suggests probably was one of the trabeculae carneae. Truex \& Copenhaver [16] as well as Sandusky and White [17] described the trabeculae only in the right ventricle. Some authors suggest that "moderator bands" are tiny muscular bands deriving directly from the septomarginal trabecula that also run towards the anterior wall. It seems reasonable to reserve the name of septomarginal trabecula, as well as moderator band, for the structures of muscular tissue found in the right ventricle of the heart. All the trabeculae deriving from the lower segment of the crista supraventricularis could be named the moderator bands, while the first branch at the side of the atrioventricular outlet, connecting with the anterior papillary muscle, should be called the septomarginal trabecula proper. Our previous observations prove that its antero-inferior surface often gives small secondary trabeculae running towards the anterior wall of the right ventricle. A similar observation was previously described by Restivo et al. [18]. Their presence, number and size can determine the course, topography and final thickness of the septomarginal trabecula. Gradually, giving away some of its fibres to the branches, it loses its mass to become, in its distal part, a poorly developed structure. In case of absence of the secondary trabeculae, its size is nearly constant along its whole length. Moreover, considering our previously published results, it can be concluded that the width of the lower part of the crista supraventricularis and consequently the number of its branches can have some influence on the size of the septomarginal trabecula.

The ratio of the height of location of the septomarginal trabecula proximal attachment to the height of the interventricular septum was another subject of analysis. The differences among the studied groups were not significant in the chisquare statistical test. Lamers et al. [1] reported that 
Table IV. The frequency of occurrence of morphological types of the septomarginal trabecula in the respective age groups

\begin{tabular}{|c|c|c|c|}
\hline Morphological types of the septomarginal trabecula & Fetuses & Children & Adults \\
\hline \multicolumn{4}{|c|}{ I. Anterior papillary muscle not connected with the trabecula } \\
\hline Sub-type a & 4 & 2 & - \\
\hline Sub-type b & 1 & 1 & 3 \\
\hline \multicolumn{4}{|c|}{ II. One-part trabecula, connecting with the anterior wall and the trunk of the anterior papillary muscle } \\
\hline Sub-type a & 4 & 3 & 7 \\
\hline Sub-type b & 9 & 6 & 1 \\
\hline \multicolumn{4}{|c|}{ III. One-part trabecula, connecting only with the trunk of the anterior papillary muscle } \\
\hline Sub-type a & 34 & 33 & 35 \\
\hline Sub-type b & 6 & 7 & 10 \\
\hline \multicolumn{4}{|l|}{ IV. Two-part trabecula } \\
\hline Sub-type a & - & 2 & 12 \\
\hline Sub-type b & 2 & 3 & 19 \\
\hline \multirow[t]{2}{*}{ Sub-type c } & - & 3 & 13 \\
\hline & 60 & 60 & 100 \\
\hline
\end{tabular}

in the early period of fetal life the septomarginal trabecula has a beginning high at the septum, and it gradually descends. Such a relation was not described in other studies and neither was the evaluation of the angle between the long axis of the trabecula and the crista supraventricularis. According to the statistical analysis the magnitude of the above-mentioned parameter depends on the type of division of the lower part of the crista supraventricularis, as well as the presence or absence of secondary trabeculae. The degree of the angle did not differ significantly between the studied groups. However, the value was slightly larger $\left(61-90^{\circ}\right)$ in the group of adults than among fetuses or children. Wide angles, independently of age, were also found in hearts with a greater number of crista supraventricularis branches. Moreover, the presence of secondary trabeculae also had an influence on the variability of the analysed parameter. Thus, the more branches the lower segment of the crista gave and the higher the trabecula began and the wider the angle of branching and the larger the number of secondary trabeculae, the longer and the thinner the trabecula was, running obliquely or horizontally across the whole width of the ventricle. On the other hand, the wider the lower segment of the crista was, with fewer or no branches and/or secondary trabeculae, the shorter the trabecula was, running steeply and vertically downwards.

The analysis of the relation between the septomarginal trabecula and the anterior papillary muscle resulted in specific types being distinguished. On the basis of the study, some attempts were made to explain the origin of the separate elements of this structure. Beninghoff [19] was first to distinguish two components: the septopapillary, connecting the septum with the anterior papillary muscle, and the papillo-marginal, running further, from the muscle towards the anterior wall. Some other scientists identify, apart from the above, also a so-called hidden part. It is the initial fragment of the septo-papillary segment immediately before its parting from the interventricular septum [4, 20, 21]. Netter [22] in his illustrated atlases presents the trabecula as a threepiece structure. According to Beninghoff [19], the proximal (septo-papillary) segment corresponds with the muscle strip in reptiles, while the distal (papillo-marginal) one originates from the net of peripheral trabeculae. Szostakiewicz-Sawicka [13, 23] later confirmed the above observation. Puff and Goerttler [24] stated that in 12-mm long human embryos the anterior papillary muscle is tightly knit to the interventricular septum and seems to become isolated from it. In other, bigger embryos, the anterior papillary muscle was located centrally, joined to the septum with a fibro-muscular band that was regarded by the authors as a septopapillary segment of the septomarginal trabecula. In 10-mm hearts of 12 fetuses the configuration was similar, but with a tendency for the muscle to be located more peripherally and parietally.

The discussed papers suggest a gradual "migration" of the muscle in the early period of fetal life, from the peri-septal, through central, to parietal location, which may result in development of the septomarginal trabecula. Probably during this process the muscle gradually consolidates with the trabecula near the anterior wall of the right 
ventricle. The distinguished morphological type III might be an illustration of that phenomenon. Only in a few cases does the septomarginal trabecula fuse with the anterior papillary muscle already in the central region of the ventricle, which leads to the development of type IVa. It is apparent that the anterior papillary muscle in the majority of cases is located parietally.

Marciniak [25] refers to the anterior papillary muscle arising from the septomarginal trabecula at the mid-point of its length, which corresponds with type IVa distinguished in the present paper. Podlecki [26] during his observations of 80 human hearts distinguished 3 types of anterior papillary muscle location depending on its relation to the septum and the lateral angle of the ventricle. In 2/3 of the studied material the muscle was located on the anterior wall or close to it, while for the remaining cases it was located intermedially. His results confirm the significantly higher incidence of parietal location of the anterior papillary muscle in the right ventricle of the heart.

In our observations, the occurrence of loose connection of the anterior papillary muscle and the septomarginal trabecula was very incidental, and in such cases the muscle, as a rule, was located at the anterior wall of the right ventricle (type I).

Data found in the literature, as well as our own, allow us to support a hypothesis of the origin of the mentioned segments of the septomarginal trabecula, as well as the sequence of changes they undergo in human ontogenesis and phylogenesis of the primates. The most primitive morphological configuration we find is the one in lemurs, where the anterior papillary muscle emerges from the interventricular septum, with concurrent absence of the septomarginal trabecula. For a more developed configuration the anterior papillary muscle has a variable location, peri-septal, central or parietal, and does not fuse tightly with the anterior wall of the right ventricle (type la). In conjunction with the "migration" of the muscle from the septum towards the wall, the septomarginal trabecula is formed. In such a case it is completely separate from the muscle. Nevertheless, the two structures are often connected by a thin band of fibrous tissue. A more advanced stage is a tight connection of the anterior papillary muscle with the muscle tissue of the anterior wall of the right ventricle. The junction of the muscle and the trabecula is also located parietally (partially in type Ila, IIb, or completely in type IIIa, IIIb). Type IV is found mainly in the hearts of adults. According to our concept, type IVa develops when the anterior papillary muscle does not reach the goal during its "migration" towards the anterior wall and fuses with a solid, well-developed septomarginal trabecula in the central part of the right ventricle (type IVa). In such cases a single, noticeable, welldeveloped papillo-marginal segment can be found, which is a continuation of the septo-papillary one. To understand the probable mechanism of type $\mathrm{IVb}$ and IVc development one should pay attention to type III. The only difference between its sub-types $a$ and $b$ was the height of junction of the muscle and the trabecula. Type Illa is an initial base for differentiating type IVb, provided it is accompanied by a poorly developed net of parietal trabeculae. With a well-developed net of parietal trabeculae one can also distinguish a short papillo-marginal segment, though with multiple branches. Its course as well as origin are very variable, because it is created by the net of parietal trabeculae and the vertical, lower part of the anterior papillary muscle (type IVc). It seems that a highly variable, multibranched papillo-marginal segment derives from type Ila or IIb. In this case it is created by the trabeculae of the parietal net, the lower part of the trunk of the anterior papillary muscle and, contrary to the previous types, possibly the distal, short, horizontal segment of the septomarginal trabecula.

The septomarginal trabecula is an important and interesting structure, not only in terms of its morphology and phylogenesis but also from the clinical viewpoint. What seems particularly important is knowledge of the formation and topography of the septomarginal trabecula in the context of cardio-surgical procedures. The structure may profoundly impede the course of closing lowlocated defects in the interventricular septum (VSD). A developed septomarginal trabecula limits the operating field and disturbs the proper localization of the foramen as well as hindering procedures at the stage of stitching $[27,28]$. Due to the conduction system fibres present within the septomarginal trabecula, its removal while dressing VSD may involve iatrogenic complications, e.g. heart block $[28,29]$. A substantial role of the described structure was observed during ablation treatment due to ventricular tachycardia. It proves that both in the trabecula and also in other elements of the right ventricle (papillary muscles, false chordae tendineae) there may occur arrhythmogenic foci [30]. On the other hand, their formation often impedes manoeuvring of the catheter, which often limits the intervention's efficiency [30]. A few reports confirm the occurrence of additional conductive ways within the septomarginal trabecula, being a morphological substrate of Mahaim tachycardia [31]. Other implications of the described structure are also present in the literature: it may cause misdiagnoses during visual examinations [32, 33] or constitute a site for a clot or bacterial vegetation [32, 34].

The present paper is one of a planned series focusing on this issue. According to our intentions, 
the next research projects will concentrate on microscopic analysis. We hope that our observations will complete and update the current knowledge in the field of form and origin of these interesting structures.

\section{References}

1. Lamers WH, Viragh Sz, Wessels A, et al. Formation of the tricuspid valve in the human heart. Circulation 1995; 91: 11-121.

2. Bielańska-Osuchowska Z. Zarys organogenezy. Różnicowanie się komórek w narządach [Polish]. PWN, Warszawa; 2004.

3. Licata RH. The human embryonic heart in the ninth week. Am J Anat 1954; 94: 73-125.

4. Grant RP, Downey FM, MacMahon H. The architecture of the right ventricular outflow tract in the normal human heart and in the presence of ventricular septal defects. Circulation 1961; 24: 223-35.

5. Tandler J. Anatomie des Herzens [German]. Gustav Fischer, Jena; 1913.

6. Leeson CR, Leeson TS. Human structure. Elsevier, NY; 1989.

7. Maron BJ, Mclntosh CL, Klues HG, Cannon RO 3'rd, Roberts WC. Morphologic basis for obstruction to right ventricular outflow in hypertrophic cardiomyopathy. Am J Cardiol 1993; 71: 1089-94.

8. Moene RJ, Oppenheimer-Dekker A, Bartelings MM. Anatomic obstruction of the right ventricular outflow tract in transposition of the great arteries. Am J Cardiol 1983; 51: 1701-4.

9. Bargmann W. Bau des Herzens. In Das Herz des Menschen [German]. W. Bargmann, W. Doerr, I. Band (eds). Georg Thieme: Stuttgart; 1963.

10. Okabe M, Fukuda K, Nakashima Y, et al. A quantitative histopathological study of right bundle branch block complicating acute anteroseptal myocardial infarction. $\mathrm{Br}$ Heart J 1991; 65: 317-21.

11. Kosiński A, Nowiński J, Kozłowski D, Piwko G, Kuta W, Grzybiak M. The crista supraventricularis in the human heart and its role in the morphogenesis of the septomarginal trabecula. Ann Anat 2007; 189: 447-56.

12. Scammon RE, Calkins LA. The development and growth of the external dimensions of the human body in the fetal period. The University of Minnesota Press, Minneapolis; 1929.

13. Szostakiewicz-Sawicka H. Zastawka przedsionkowakomorowa prawa u naczelnych [Polish]. Acta Biol Med Soc Sci Gedan 1967; 11: 545-636.

14. Gerlis LM, Wright HM, Wilson N, Erzengin F, Dickinson DF. Left ventricular bands. Br Heart J 1984; 52: 641-7.

15. Turner W. Moderator band in left ventricle and tricuspid left auriculo-ventricular valve. J Anat 1898; 32: 372-6.

16. Truex RC, Copenhaver WM. Histology of the moderator band in man and other mammals with special reference to the conduction system. Anat Rec 1944; 85: 451-6.

17. Sandusky GE, White SL. Scanning microscopy of the canine atrioventricular bundle and moderator band. Am J Vet Res 1985; 46: 249-52.

18. Restivo A, Smith A, Wilkinson JL, et al. The medial papillary muscle complex and its related to septomarginal trabeculation. A normal anatomical study on human hearts. J Anat 1989; 163: 231-42.

19. Benninghoff A. Lehrbuch der Anatomie des Menschen [German]. Band II, Teil 1. Lehmanns, München-Berlin; 1942.
20. Dudziak M, Szostakiewicz-Sawicka H, Amerski L. Septomarginal trabecula in the right cardiac ventricle of some carnivores. Folia Morphol (Warsz) 1984; 43: 271-5.

21. Rowland T, Rosenthal A, Castaneda A. Double-chamber right ventricle: experience with 17 cases. Am Heart J 1975; 89: 455-62.

22. Netter FH. Farbatlanten der Medizin [German]. Band I, Herz. Georg Thieme, Stuttgart-New York; 1990.

23. Szostakiewicz-Sawicka $\mathrm{H}$. The anterior papillary muscle of the right ventricle. Folia Morphol (Warsz) 1968; 27: 371-81.

24. Puff A, Goerttler U. Die Entwicklung der großen Papillarmuskels der rechten Kammer unter besonderer Berücksichtigung der Bildung der Einströmungsbahn [German]. Morph Jahrb 1963; 105: 292-316.

25. Marciniak T. Anatomy of the human [Polish]. Tom II. Akademia Medyczna, Wrocław; 1991.

26. Podlecki K. Morphology of the anterior papillary muscle in the right ventricle in human heart. Folia Morphol (Warsz) 1987; 46: 187-97.

27. Yoshimura N, Matsuhisa H, Otaka S, et al. Surgical management of multiple ventricular septal defects: The role of the felt sandwich technique. J Thorac Cardiovasc Surg 2009; 137: 924-8.

28. Loukas M, Klaassen Z, Tubbs RS, et al. Anatomical observations of the moderator band. Clin Anat 2010; 23: 443-50.

29. Kurosawa H, Becker AE. Surgical anatomy of the atrioventricular conduction bundle in anomalous muscle bundle of the right ventricle with subarterial ventricular septal defect. Pediatr Cardiol 1986; 6: 157-60.

30. Abouezzeddine $O$, Suleiman $M$, Buescher $T$, et al. Relevance of endocavitary structures in ablation procedures for ventricular tachycardia. J Cardiovasc Electrophysiol 2010; 21: 245-54.

31. Jongbloed MR, Wijffels MC, Schalij MJ, et al. Development of the right ventricular inflow tract and moderator band: a possible morphological and functional explanation for Mahaim tachycardia. Circ Res 2005; 96: 776-83.

32. Kim DH, Choi SI, Choi JA, et al. Various findings of cardiac thrombi on MDCT and MRI. J Comput Assist Tomogr 2006; 30: 572-7.

33. Winn VD, Sonson J, Filly RA. Echogenic intracardiac focus: potential for misdiagnosis. J Ultras Med 2003; 22: 1207-16.

34. Koshy AG, Kanjirakadavath B, Velayudhan RV, et al. Right ventricular mural bacterial endocarditis: vegetations over moderator band. Circulation 2009; 119: 899-901. 